\title{
Reply from the authors of the article entitled "Atypical presentation of chronic granulomatous disease in an adolescent boy with frontal lobe located Aspergillus abscess mimicking intracranial tumor"
}

\author{
Ekrem Unal • Ali Yikilmaz • Turkan Patiroglu
}

Received: 28 March 2010 /Accepted: 7 April 2010 /Published online: 21 April 2010

(C) Springer-Verlag 2010

\section{Dear Editor,}

Thank you for the opportunity to respond to Dr. Turgut's comments regarding the mentioned article entitled "Atypical presentation of chronic granulomatous disease in an adolescent boy with frontal lobe located Aspergillus abscess mimicking intracranial tumor" [1]. We would like to point out our answers to the comments and criticisms by the same order:

1. - We wanted to emphasize that the survival rates of patients with chronic granulomatous disease (CGD) have dramatically increased since its initial description. Although life-threatening infections continue to occur, diagnostic and treatment opportunities have improved as well, making CGD a disease that is eminently survivable [2].

E. Unal $(\bowtie) \cdot$ T. Patiroglu

Department of Pediatrics, Division of Pediatric

Hematology and Oncology, Erciyes University,

Kayseri, Turkey

e-mail: drekremunal@yahoo.com.tr

A. Yikilmaz

Department of Radiology, Division of Pediatric Radiology,

Erciyes University,

Kayseri, Turkey
2. - Aspergillus fumigatus was isolated from the surgical specimens; besides, the pathological confirmation of the fungal infection was performed as well.

3. - As we mentioned in our article, the patient was hospitalized and treated with liposomal amphotericin $\mathrm{B}$, variconazole, and interferon gamma for 3 months. The patient has been followed in our outpatient clinic for 15 months without any sequela or complication at the time that this paper was written.

By the way, we apologize for the uncited reference by Cohen at al. [3].

We present these important points for the attention of the readers of Child's Nervous System, and thank Dr. Turgut for his valuable comments.

\section{References}

1. Patıroglu T, Unal E, Yıkılmaz A, Koker MY, Ozturk MK (2010) Atypical presentation of chronic granulomatous disease in an adolescent boy with frontal lobe located Aspergillus abscess mimicking intracranial tumor. Childs Nerv Syst 26:149-154

2. Wintergerst U, Rosenzweig SD, Abinun M, Malech HL, Holland SM, Rezaei N (2008) Phagocytes defects. In: Rezaei N, Aghamohammadi A, Notarangelo LD (eds) Primary immunodeficiency diseases. Springer, Berlin, pp 143-149

3. Cohen MS, Isturiz RE, Malech HL, Root RK, Wilfert CM, Gutman L, Buckley RH (1981) Fungal infection in chronic granulomatous disease. The importance of the phagocyte in defense against fungi. Am J Med 71:59-66 